\title{
Clinical usefulness of red cell distribution width to angiographic severity and coronary stent thrombosis
}

This article was published in the following Dove Press journal:

International Journal of General Medicine

9 September 2016

Number of times this article has been viewed

\author{
Aysun Erdem' \\ Ufuk Sadik Ceylan' \\ Aycan Esen' \\ Ertugrul Zencirci ${ }^{2}$ \\ Birol Topcu ${ }^{3}$ \\ Kivilcim Ozden' \\ Selcuk Yazici' \\ Sait Terzi' \\ Ayse Emre' \\ Kemal Yesilcimen' \\ 'Department of Cardiology, Siyami \\ Ersek Thoracic and Cardiovascular \\ Surgery Training and Research \\ Hospital, Istanbul, Turkey; \\ ${ }^{2}$ Department of Cardiology, Acibadem \\ Hospital Maslak, Istanbul, Turkey; \\ ${ }^{3}$ Department of Biostatistics, Faculty \\ of Medicine, Namik Kemal University, \\ Tekirdag, Turkey
}

Correspondence: Aysun Erdem Rıhtım Caddesi, Nemlizade Sok, No 9/5, Kadikoy, Istanbul, Turkey

Tel +905333252733

Fax +90 2I 22859314

Emailerdemaysun@yahoo.com
Background: Red cell distribution width (RDW) is a quantitative measurement and shows heterogeneity of red blood cell size in peripheral blood. RDW has recently been associated with cardiovascular events and cardiovascular diseases, and it is a novel predictor of mortality. In this study, we aimed to evaluate the clinical usefulness of measuring RDW in patients with coronary stent thrombosis.

Patients and methods: We retrospectively reviewed 3,925 consecutive patients who presented with acute coronary syndrome and who underwent coronary angiography at the Siyami Ersek Hospital between May 2011 and December 2013. Of the 3,925 patients, 73 patients (55 males, mean age $59 \pm 11$ years, 55 with ST elevated myocardial infarction) with stent thrombosis formed group 1 . Another 54 consecutive patients who presented with acute coronary syndrome (without coronary stent thrombosis, 22 patients with ST elevated myocardial infarction, 44 males, mean age 54 \pm 2 years) and underwent percutaneous coronary intervention in May 2011 formed group 2. Data were collected from all groups for 2 years. The RDW values were calculated from patients 1 month later at follow-up. Syntax scores were calculated for all the patients. The patients were also divided as low syntax score group and moderate-high syntax score group.

Results: The patients in group 1 with stent thrombosis had significantly higher RDW level (13.85) than the patients in group 2 without stent thrombosis $(12)(P<0.001)$. In addition, in all study patients, the moderate-high syntax score group had significantly higher RDW level (13.6) than the low syntax score group (12.9) $(P=0.009)$. A positive correlation was determined between RDW and syntax scores $(r=0.204)$.

Conclusion: RDW is a new marker of poor prognosis in coronary artery disease. Increased RDW level is correlated with angiographic severity of coronary artery disease, and RDW may be an important clinical marker of coronary stent thrombosis in patients undergoing coronary intervention.

Keywords: syntax score, stent thrombosis, red cell distribution width, coronary artery disease

\section{Introduction}

The red cell distribution width (RDW) is a measurement of size variation and an index of the heterogeneity of erythrocytes, which is calculated by dividing the standard deviation of red blood cell volume by the mean corpuscular volume and multiplying by 100 to express the result as a percentage. The normal reference range of RDW spans between $11 \%$ and $14 \% .{ }^{1}$ In recent studies, the predictive and prognostic value of RDW levels has been shown in several cardiovascular diseases. High RDW values were also shown to be associated with increased mortality with coronary artery 
disease (CAD). ${ }^{2} \mathrm{~A}$ few studies demonstrated that higher RDW, even within the normal reference range, was strongly associated with increased risk of death and cardiovascular events in middle-aged and older adults. ${ }^{3}$ Stent thrombosis is a rare but mortal condition, due to which predictors of stent thrombosis were investigated in many studies. ${ }^{4}$ Several studies have reported an association between inflammation and stent thrombogenicity. However, there are limited trials that studied the relationship between RDW and the risk of stent thrombosis in patients with CAD. Therefore, in this study, we examined the clinical usefulness of RDW value in patients with coronary stent thrombosis.

\section{Patients and methods}

\section{Study population}

We retrospectively reviewed 3,925 consecutive patients who presented with acute coronary syndrome and who underwent coronary angiography at the Siyami Ersek Hospital between May 2011 and December 2013. Of the 3,925 patients, 73 patients (55 males, mean age $59 \pm 11$ years, 55 with ST elevated myocardial infarction [STEMI]) with stent thrombosis formed group 1. Another 54 consecutive patients who presented with acute coronary syndrome (without coronary stent thrombosis, 22 patients with STEMI, 44 males, mean age $54 \pm 2$ years) and underwent percutaneous coronary intervention (PCI) on May 2011 formed group 2. Data were collected from both groups for 2 years. Only one patient in group 2 had stent thrombosis during the 2 years. This patient was excluded from the study. Patients who had blood transfusion within 4 months, malignancy, connective tissue disease, and hematological disease were excluded from the study. The study was approved by Siyami Ersek Hospital review board. This retrospective study was deemed exempt written informed consent by the Siyami Ersek Hospital review board because it used only retrospective, de-identified patient data.

\section{Methods}

\section{Coronary angiography and angioplasty}

Group 1 and group 2 patients underwent angiography using the Judkins technique. Severity of CAD was determined with syntax score. Low syntax score was defined as $<23$, and moderate-high syntax score was defined as $\geq 23$. PCI of patients in the groups was done according to the European Society of Cardiology guidelines. ${ }^{5-7}$

\section{Laboratory measurements}

The RDW and other laboratory values were obtained from the collected data 1 month after the intervention.

\section{Statistical analysis}

Predictive Analytics SoftWare (PASW), Statistics 18 (SPSS Inc, Chicago, USA) for Windows program was used for data input and statistical analysis. Mean, median, standard deviation, and minimum and maximum values were used to describe the results. Kolmogorov-Smirnov test was used to test data normality. Independent-samples $t$-test was used to compare two groups showing normal distribution, and Mann-Whitney $U$ test was used to compare two groups with abnormal distribution. Chi-square analysis was used for categorical data comparison. Pearson's and Spearman correlation analysis tests were used to determine the correlation between variables. Values of $P<0.05$ were considered to be statistically significant.

\section{Results}

Demographic and clinical characteristics of the study groups are presented in Table 1. Group 1 and group 2 were similar in terms of sex distribution. Mean age was higher in group 1 $(59.87 \pm 11.02$ years) than in group $2(54.37 \pm 1.79$ years $)$ $(P=0.01)$. Both groups had similar diabetes rates, but hypertension was more frequent in stent thrombosis group (group $1 \mathrm{n}$ : 58, group $2 \mathrm{n}: 29, P=0.003$ ). Hemoglobin levels were lower in patients with stent thrombosis (group $1 \mathrm{Hb}$ : $13 \mathrm{mg} / \mathrm{dL}$, group $2 \mathrm{Hb}: 14 \mathrm{mg} / \mathrm{dL}, P=0.001$ ). Mean platelet volume and white blood cell levels of the groups were similar. Creatinine, triglyceride, and high-density lipoprotein levels were similar. Group 2 had higher levels of low-density lipoprotein $(P=0.04)$. C-reactive protein (CRP) levels were higher in patients with stent thrombosis (group 1 CRP: 0.7, group 2 CRP: $0.3, P=0.001)$. There were eleven patients with aspirin resistance in group 1, while group 2 had none $(P=0.001)$. Both groups had similar clopidogrel resistance rates. Mean ejection fraction was 50\% (20-60) in group 1 and 55\% (35-65) in group $2(P=0.01)$.

Comparison of syntax scores showed that group 2 had lower syntax scores (group 1 mean syntax score was 12.90 [2.00-42.00], and mean syntax score of group 2 was 10.00 [1.00-36.00], $P=0.009$ ). Drug-eluting stent (DES) was higher in group 1 (DES group 1, $\mathrm{n}=33$; DES group 2, $\mathrm{n}=11 ; P=0.001$ ).

RDW value was 13.85 (11.40-18.70) in group 1 and $12.00(10.70-14.00)$ in group $2(P<0.001)$. Figure $1 \mathrm{dem}-$ onstrates the comparison of RDW values between group 1 and group 2. There was no relation between RDW and the timing of occurrence of stent thrombosis (stent thrombosis in the first 24 hours after implantation [ $n=16]$ RDW $14.05 \pm 0.65,24$ hours-1 month [n=31] RDW 14.42 \pm 1.94 , 1 month-1 year [n=20] RDW 13.96 \pm 1.35 , after 1 year $[\mathrm{n}=7]$ RDW 14 $\pm 2.01, P=0.8)$. Group 1 with low syntax score $(\mathrm{n}=51)$ had a mean RDW value of 13.75 (11.40-18.70), and group 
Table I Demographic and clinical characteristics of the study groups

\begin{tabular}{|c|c|c|c|c|c|}
\hline & \multicolumn{2}{|c|}{ Stent thrombosis n=73; Group I } & \multicolumn{2}{|c|}{ Group 2, n=53 } & \multirow[t]{2}{*}{$P$-value } \\
\hline & $\mathbf{n}$ & Mean \pm SD or median (QI-Q3) & $\bar{n}$ & Mean \pm SD or median $(Q \mathrm{I}-\mathrm{Q} 3)$ & \\
\hline Age (years) & & $59.87 \pm 11.02$ & & $54.37 \pm 1.79$ & 0.01 \\
\hline \multicolumn{6}{|l|}{ Sex } \\
\hline Male & 55 & & 44 & & 0.3 \\
\hline Hypertension & 58 & & 29 & & 0.003 \\
\hline Diabetes mellitus & 28 & & 14 & & 0.1 \\
\hline Sleep apnea & 8 & & 1 & & 0.051 \\
\hline Prior MI & 36 & & 37 & & 0.02 \\
\hline COPD & 0 & & 5 & & 0.01 \\
\hline LDL (mg/dL) & & $107.75 \pm 32.64$ & & $120.64 \pm 37.40$ & 0.04 \\
\hline $\mathrm{HDL}(\mathrm{mg} / \mathrm{dL})$ & & $38(22.00-70.00)$ & & $37.00(26.00-62.00)$ & 0.80 \\
\hline Triglycerides (mg/dL) & & $132(47-927)$ & & $130(42-939)$ & 0.99 \\
\hline Creatinine (mg/dL) & & $0.9(0.5-1.6)$ & & $0.9(0.5-1.4)$ & 0.45 \\
\hline RDW (\%) & & $13.85(\mid 1.40-18.70)$ & & $12.00(10.70-14.00)$ & 0.001 \\
\hline WBC $\left(10^{3} / \mathrm{mm}^{3}\right)$ & & $9.00(4.4-21.00)$ & & $9.00(5-18.00)$ & 0.4 \\
\hline MPV (fl) & & $8.9(7.00-11.30)$ & & $8.7(7.00-13.00)$ & 0.5 \\
\hline Hemoglobin $(\mathrm{g} / \mathrm{dL})$ & & $13(6.9-17.00)$ & & $14(11.00-16.00)$ & 0.001 \\
\hline hs CRP (mg/L) & & $0.7(0.1-7.9)$ & & $0.3(0.1-1.4)$ & 0.001 \\
\hline Aspirin resistance & 11 & & 0 & & 0.01 \\
\hline Clopidogrel resistance & 12 & & 3 & & 0.17 \\
\hline Syntax score & & $12.9(2.00-42.00)$ & & $10(1.00-36.00)$ & 0.001 \\
\hline $\mathrm{EF}$ & & $50(20-60)$ & & $55(35-65)$ & 0.01 \\
\hline DES use & 33 & & 11 & & 0.001 \\
\hline
\end{tabular}

Abbreviations: MI, myocardial infarction; COPD, chronic obstructive pulmonary disease; LDL, low-density lipoprotein; HDL, high-density lipoprotein; RDW, red cell distribution width; WBC, white blood cell; MPV, mean platelet volume; hs CRP, high-sensitivity C-reactive protein; EF, ejection fraction; DES, drug-eluting stent; SD, standard deviation.

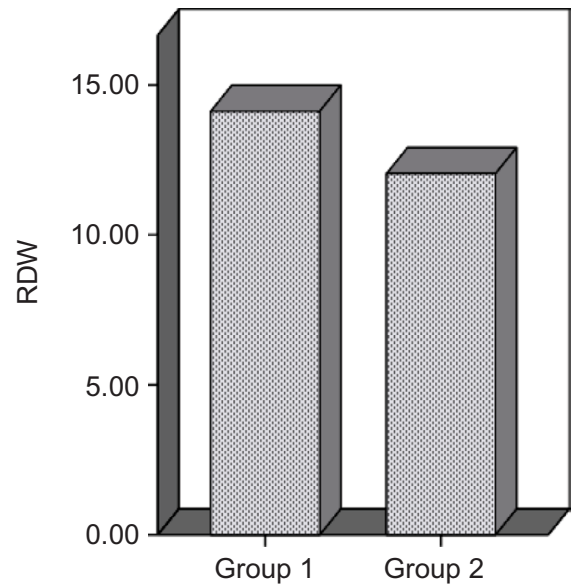

Figure I Comparison of values of RDW\% between cases (group I) and controls (group 2).

Abbreviation: RDW, red cell distribution width.

2 with low syntax score $(\mathrm{n}=46)$ had a mean RDW value of $12.00(10.70-14.00)(P<0.01)$. Group 1 with moderatehigh syntax score $(\mathrm{n}=22)$ had a mean RDW value of 14.15 (12.10-18.70), and group 2 with moderate-high syntax score $(\mathrm{n}=7)$ had a mean RDW value of $12.40(11.80-12.90)$ $(P<0.01)$. In group 1 , there was no significant difference between patients with low syntax score and moderate-high syntax score $(P>0.05)$. These results are presented in Table 2 . When the patient groups with and without stent thrombosis
Table 2 The relationship between of syntax scores and RDW values.

\begin{tabular}{llllll}
\hline $\begin{array}{l}\text { Syntax } \\
\text { scores }\end{array}$ & $\begin{array}{l}\text { Group I } \\
\mathbf{n}\end{array}$ & $\begin{array}{l}\text { Group 2 } \\
\mathbf{n}\end{array}$ & $\begin{array}{l}\text { Group I } \\
\text { RDW }\end{array}$ & $\begin{array}{l}\text { Group 2 } \\
\text { RDW }\end{array}$ & P-value \\
\hline Low $<23$ & 51 & 46 & 13.75 & 12.00 & $<0.01$ \\
& & & $(11.40-18.70)$ & $(10.70-14.00)$ & \\
Moderate- 22 & 7 & 14.15 & 12.40 & $<0.01$ \\
high $>23$ & & & $(12.00-18.70)$ & $(11.80-12.90)$ & \\
Total & 73 & 53 & $\begin{array}{l}13.85 \\
(11.40-18.70)\end{array}$ & $\begin{array}{l}12.00 \\
(10.70-14.00)\end{array}$ & $<0.001$ \\
\hline
\end{tabular}

Note: RDW data presented as mean (minimum-maximum).

Abbreviation: RDW, red cell distribution width.

were combined, mean RDW levels were 12.9 (10.70-18.70) in patients with a low syntax score and $13.6(11.80-18.70)$ in patients with moderate-high syntax score $(P=0.09)$. A positive correlation was determined between RDW level and syntax score when the groups were combined $(r=0.204)$. This is further highlighted in Figure 2. Group 1 with aspirin resistance had a mean RDW value of $13.6 \pm 1.8$, and group 1 without aspirin resistance had a mean RDW value of $14.2 \pm 1.6$. There was no significant difference between patients with and without aspirin resistance $(P=0.33)$. The higher $C R P$ and lower ejection fraction values had no influence on the RDW level in group 1 and group $2(P<0.05)$. The RDW values were not significantly different according to DES usage in group 1 and group 2 . The decrease in hemoglobin level was correlated with an increase in RDW $(P=0.01)$. 


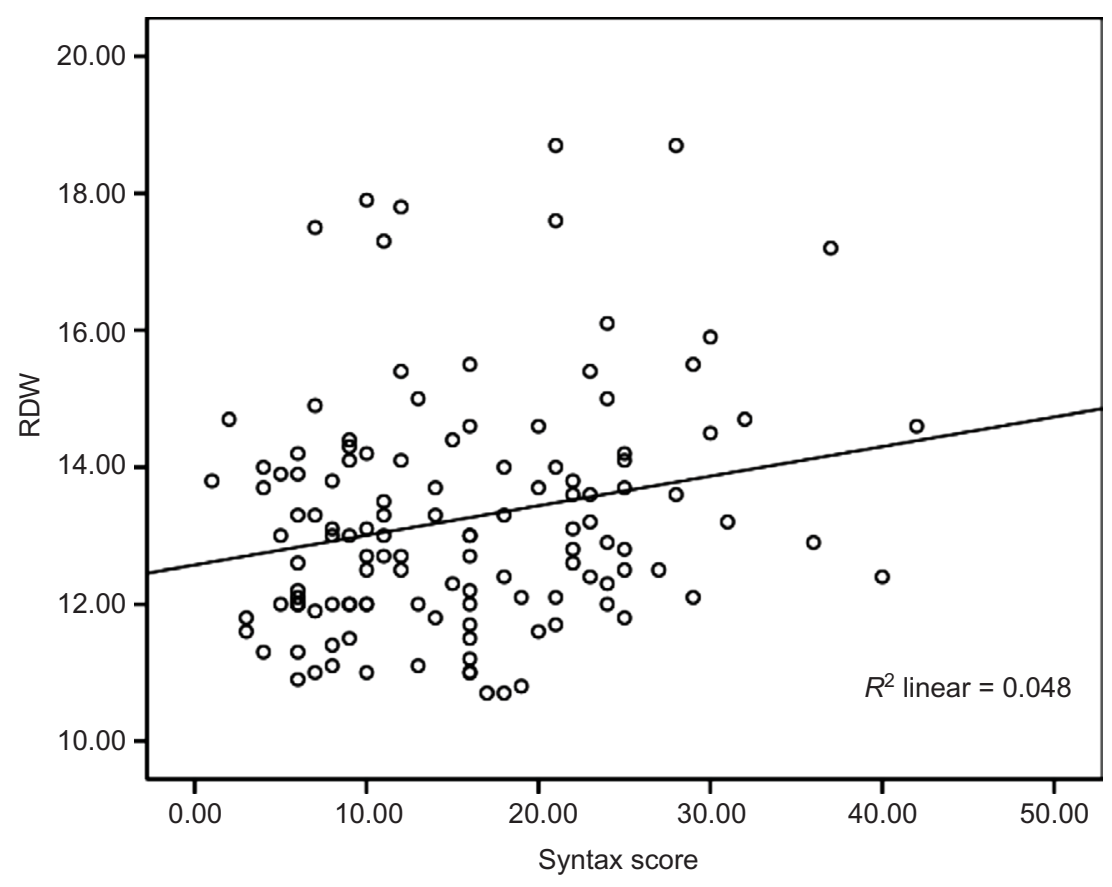

Figure 2 Statistical correlation between RDW\% and syntax score.

Abbreviation: RDW, red cell distribution width.

\section{Discussion}

Stent thrombosis occurs in $0.5 \%-1 \%$ of patients within 1 year. It has been associated with 30-day mortality rate of $10 \%-25 \%$. Approximately $20 \%$ of patients with a first stent thrombosis experience a recurrent stent thrombosis episode within 2 years. The mechanism underlying stent thrombosis is multifactorial..$^{8-11}$

RDW is a parameter that is routinely reported as part of the complete blood count. In recent years, the predictive and prognostic value of RDW has been shown in several cardiovascular diseases and events. ${ }^{1-3}$ Although the exact physiological mechanisms between increased RDW and atherosclerosis are unknown, oxidative stress, inflammation, and increase in cholesterol levels in erythrocyte membrane are responsible for erythrocyte malformation; thus, they increase RDW levels. Inflammation or oxidative stress might contribute to an increased RDW by impairing iron metabolism, inhibiting the production of or response to erythropoietin, and shortening red blood cell survival. ${ }^{12,13}$ Lippi et a $\mathrm{l}^{14}$ stated that there is an increase in RDW levels during acute coronary syndrome. They showed the clinical usefulness of RDW for the risk stratification of these patients over a 1-year period. When the cutoff value of RDW was $14 \%$, the sensitivity and specificity of RDW were $79 \%$ and $50 \%$, respectively.
In our study, the RDW levels of the group that has stent thrombosis are higher than those of the other group without stent thrombosis. There was no relation between RDW and timing of occurrence of stent thrombosis. Similar to the previous studies, high RDW levels are associated with risk factors (age, hypertension, hyperlipidemia, high CRP levels). ${ }^{3,4,15,16}$ Increased RDW has been shown to be correlated with severity of coronary atherosclerosis. ${ }^{17}$ In this study, RDW levels increased as the syntax scores increased. These findings support the study by Fatemi et al, which showed high RDW levels in patients with two or more vessel disease. ${ }^{17}$ In another study, it was reported that RDW levels increased even in patients with early phase of atherosclerosis. ${ }^{2}$ Vaya et a ${ }^{18}$ studied 119 patients with acute myocardial infarction and concluded that RDW levels $>14$ are associated with a sixfold increase in cardiovascular events even after adjusting for anemia. During the follow-up period, 30 patients developed a recurrent cardiovascular event in their study. However, they did not find an association between high-sensitivity CRP and the risk of developing future cardiovascular events.

Osadnik et a ${ }^{19}$ studied the effects of RDW levels on longterm prognosis over 2 years in 2,550 stable angina pectoris patients who underwent PCI, and they showed that mortality is four times higher in patients with a high RDW level. They 
could not demonstrate a relationship between RDW and stent thrombosis rate. The association of RDW and long-term mortality in patients undergoing PCI was observed by Fatemi et $\mathrm{al}^{17}$ and Poludasu et al. $^{20}$ Poludasu et $\mathrm{al}^{20}$ also reported that RDW was a predictor of mortality in patients who had hemoglobin values exceeding $10.4 \mathrm{~g} / \mathrm{dL}$. That study excluded patients who had STEMI. ${ }^{20}$ In our study, the mean hemoglobin levels in group 1 and group 2 were $13 \mathrm{~g} / \mathrm{dL}$ and $14 \mathrm{~g} / \mathrm{dL}$, respectively. This difference was statistically significant, and lower hemoglobin values were associated with increasing RDW values. Fatemi et a ${ }^{17}$ investigated the prognostic value of RDW in 1,689 patients treated with stent implantation for 1 year. That study included 55 patients with hemoglobin $<10.4 \mathrm{~g} / \mathrm{dL}$ and 150 patients who had STEMI. The authors analyzed whether there was a significant difference between RDW quartiles and death, myocardial infarction (MI), and combined events, but not of unplanned revascularization. ${ }^{17}$ Additionally, stent type did not change the results for RDW in that study. Yao et $\mathrm{al}^{21}$ demonstrated that high RDW was associated with an increased risk of all cause death, cardiac death, and with stent thrombosis in nonanemic patients with CAD treated with DES. They did not measure high-sensitivity CRP in most of the patients. In our study, CRP levels are high in patients with high RDW level and stent thrombosis as well. But high CRP values were not associated with increasing RDW values $(P>0.05)$. The other studies showed that patients who are resistant to aspirin are at greater risk of adverse cardiovascular events regardless of the assay used to measure aspirin resistance..$^{22,23}$ In our study, aspirin resistance was more frequent in the stent thrombosis group. There was no relation between RDW and aspirin resistance. There is also no known association between aspirin and clopidogrel resistance and RDW levels. ${ }^{19}$ Based on these studies, we can conclude that high RDW level may be the reason for high stent thrombosis rates.

Even though patients with anemia were excluded, lower hemoglobin values in the stent thrombosis group may contribute to the increase of RDW levels. It can be considered as a limitation of this study. Another limitation is that iron, vitamin B12, and folate levels were not measured.

\section{Conclusion}

In this study, high RDW level was associated with increased risk of stent thrombosis, but it was not related to the timing of occurrence of stent thrombosis. Increased RDW was also correlated with angiographic severity of CAD. More studies with large patient population are needed to support its prognostic significance in patients undergoing PCI who are at risk of stent thrombosis. RDW may be an important clinical marker to estimate the coronary stent thrombosis in PCI.

\section{Acknowledgment}

This research received no specific grant from any funding agency in the public, commercial, or nonprofit sectors.

\section{Author contributions}

AE, BT, and USC conceived and designed the study. A Erdem, KO, A Emre, and EZ performed the experiments. A Esen, SY, ST, and BT analyzed and interpreted the data. A Erdem and KY wrote the manuscript and revised the manuscript. All authors contributed toward data analysis, drafting and critically revising the paper and agree to be accountable for all aspects of the work.

\section{Disclosure}

The authors report no conflicts of interest in this work.

\section{References}

1. Montagnana M, Cervellin G, Meschi T, Lippi G. The role of red cell distribution width in cardiovascular and thrombotic disorders. Clin Chem Lab Med. 2012;50(4):635-641.

2. Wen Y. High red cell distrubition width is closely associated with risk of carotid artery atherosclerosis in patients with hypertension. Exp Clin Cardiol. 2010;15(3):37-40.

3. Patel K, Semba R, Ferrucci L, et al. Red cell distribution width and mortality in older adults: a meta analysis. J Gerontol A Biol Sci Med Sci. 2010;65(3):258-265.

4. Malandrino N, Wu W, Taveira H, Whitlatch H, Smith J. Association between red cell distribution width and macrovascular and microvascular complications in diabetes. Diabetologia. 2012;55(1):226-235.

5. Kirtane A, Stone G. How to minimize stent thrombosis. Circulation. 2011;124(11):1283-1287.

6. Kappetein A, Feldman T, Mack M, et al. Comparison of coronary bypass surgery with drug eluting stenting fort the treatment of left main and/ or three-vessel disease: 3- year follow-up of the SYNTAX trial. Eur Heart J. 2011;32(17):2125-2134.

7. Shiomi H, Marimoto T, Hayano M, et al; CREDO-Kyoto PCI/CABG Registry Cohort-2 Investigators. Comparison of long-term outcome after percutaneous coronary intervention versus coronary bypass grafting in patients with unprotected left main coronary artery disease (from the CREDO-Kyoto PCI/CABG registry cohort-2). Am J Cardiol. 2012;110(7):924-932.

8. Kolh P, Danchin N, Alfonso F, et al. Guidelines on myocardial revascularization. Eur Heart J. 2010;31(20):2501-2555.

9. Windecker S, Meier B. Late coronary stent thrombosis. Circulation. 2007;116(17):1952-1965.

10. Zang Q, Li Y, Wang X, et al. Incidence and predictors of definite stent thrombosis after coronary stent implantation. Chin Med J. 2012;125(9):1547-1551.

11. Buchanan G, Basavarajaiah S, Chieffo A. Stent thrombosis: incidence, predictors and new technology. Thrombosis. 2012;2012:956962.

12. Kalay N, Aytekin M, Kaya M, et al. The relationship between inflammation and slow coronary flow:increased red cell distribution width and serum uric acid levels. Arch Turk Soc Cardiol. 2011;39(6):463-468.

13. Tziakas D, Chalikias G, Grapsa A, Gioka T, Tentes I, Konstantinides S. Red blood cell distribution width-a strong prognostic marker in cardiovascular disease-is associated with cholesterol content of erythrocyte membrane. Clin Hemorheol Microcirc. 2012;51(4):243-254. 
14. Lippi G, Filippozzi L, Montagnana M, et al. Clinical usefulness of measuring red blood cell distribution width on admission in patients with acute coronary syndromes. Clin Chem Lab Med. 2009;47(3): 353-357.

15. Azab B, Torbey E, Hatoum H, et al. Usefulness of red cell distribution width in predicting all- cause long-term mortality after non ST elevation myocardial infarction. Cardiology. 2011;119(2):72-80.

16. Al- Najjar Y, Goode KM, Zhang J, Cleland JG, Clark AL. Red cell distribution width: an inexpensive and powerful prognostic marker in heart failure. Eur J Heart Fail. 2009;11(12):1155-1162.

17. Fatemi O, Paranilam J, Rainow A, et al. Red cell distribution width is a predictor of mortality in patients undergoing percutaneous coronary intervention. J Thromb Thrombolysis. 2013;35(1):57-64.

18. Vaya A, Hernandez J, Zorio E, Bautista D. Association between red blood cell distribution width and the risk of future cardiovascular events. Clin Hemorheol Microcirc. 2012;50(3):221-225.
19. Osadnik T, Strzelczyk J, Hawranek M, et al. Red cell distribution width is associated with long term prognosis in patients with stable coronary artery disease. BMC Cardiovasc Disord. 2013;13:113.

20. Poludasu S, Marmur JD, Weedon J, Khan W, Cavusoglu E. Red cell distrubition width (RDW) as a predictor of long-term mortality in patients undergoing percutaneous coronary intervention. Thromb Haemost. 2009;102(3):581-587.

21. Yao H, Sun T, Zhang X, et al. Red blood cell diatrubition width and longterm outcome in patients undergoing percutaneous coronary intervention in the drug-eluting stenting era: a two year cohort study. PLoS One. 2014;9(4):e94887.

22. Krasopoulos G, Brister S, Beattie S, Buchanan M. Aspirin resistance and risk of cardiovascular morbidity: systematic review and meta analysis. BMJ. 2008;336(7637):195-198.

23. Biondi G, Lotrionte M. Aspirin resistance in cardiovascular disease. BMJ. 2008;336:165-167.
International Journal of General Medicine

\section{Publish your work in this journal}

The International Journal of General Medicine is an international, peer-reviewed open-access journal that focuses on general and internal medicine, pathogenesis, epidemiology, diagnosis, monitoring and treatment protocols. The journal is characterized by the rapid reporting of reviews, original research and clinical studies across all disease areas.

\section{Dovepress}

The manuscript management system is completely online and includes a very quick and fair peer-review system, which is all easy to use. Visit http://www.dovepress.com/testimonials.php to read real quotes from published authors.

Submit your manuscript here: https://www.dovepress.com/international-journal-of-general-medicine-journal 